\title{
Impact Evaluation of A Grant Program for Postgraduate Studies Undertaken Abroad: Analysis of the Ecuadorian Case
}

\author{
Juan Ponce ${ }^{1} \&$ Nilo M. Cedeño ${ }^{2}$ \\ ${ }^{1}$ Facultad Latinoamericana de Estudios Sociales - FLACSO, Quito, Ecuador \\ ${ }^{2}$ Krannert Graduate School of Management, Purdue University, USA \\ Correspondence: Juan Ponce, Facultad Latinoamericana de Estudios Sociales - FLACSO, Quito, Ecuador.
}

Received: May 14, 2021

Accepted: June 13, 2021

Online Published: June 16, 2021

doi:10.5430/ijhe.v10n6p83

URL: https://doi.org/10.5430/ijhe.v10n6p83

\begin{abstract}
The National Secretary for Higher Education, Science, Technology and Innovation in Ecuador (locally SENESCYT) started an ambitious grants program in 2011. The main objective of the program was to send Ecuadorian students to undertake postgraduate studies at universities overseas. This article evaluates the impact of this grant policy on the labor income of the beneficiaries after they have completed their studies abroad and returned to Ecuador. Using a fixed-effects with lagged dependent variable model combined with a propensity score matching, we find a negative impact on the income of the grant holders during the first year following their return to the country. For the second year, the effect is non-significant. During the third year, the impact becomes significant and positive. The grant holders who returned having completed their postgraduate program abroad had a $9 \%$ higher employment income in the third year than those who did their postgraduate studies in Ecuador. The program's effect concentrates on women, the low-income group, and on those beneficiaries that studied in the USA.
\end{abstract}

Keywords: Ecuador, impact evaluation, labor income, postgraduate, grant program, fixed-effects, and lagged dependent variables with propensity score matching

\section{Introduction}

The effect of education on future employment income is widely recognized in the literature on human capital. In this regard, the classic works by Becker (1962 \& 1964), Mincer (1970), and Schultz (1975) formally and empirically established the potential link between investing in education today to achieve better labor income in the future.

There is extensive empirical literature that analyzes the relationship between education and labor income, both for developed and developing countries. For example (Psacharopoulos \& Patrinos, 2004) reviewed the educational returns for different regions of the world. A critical conclusion in this review was that for developing countries, the educational returns are more significant than for developed countries.

There is also crucial empirical literature that analyzes the effect of research grants on scientific or technological knowledge. As an example for the United States, see (Arora \& Gambardella, 2005). For Latin America see (Chudnovsky et al., 2006), (Ubfal \& Maffioli, 2011), (Benavente et al., 2012), and (Benavente et al., 2007).

Regarding the theory of human capital argument, having a postgraduate qualification improves future labor income. Some studies confirm this relationship for Latin America. See, for example, (Cubillos Calderón et al., 2016) and (Mendoza, 2014).

More specifically, the literature also shows that grant programs for international mobility for postgraduate studies, positively affect the development of the human capacities of the beneficiaries. See, for example, (Vincent-Lancrin, 2011), (Fierro \& Ponce, 2017), (Bonilla Landaverry \& Kwak, 2015), (Aggio et al., 2017).

The empirical evidence is scarce in relation to the impact of grant programs on labor and income in Latin America is scarce. Bonilla Landaverry \& Kwak (2015) found that in grant programs for postgraduates in Guatemala, almost $90 \%$ of the holders reported a salary increase once they had concluded their studies, while the remaining $10 \%$ indicated that their remuneration stayed the same. This study involved 84 grant beneficiaries. The study did not have a control group. In the same line, Luchilo (2009) did a descriptive analysis of the occupational trajectory of Mexican students who received a CONACYT (National Council of Science and Technology) grant between 1997 and 2006. He found that the former grant holders, who completed their master's abroad, had an employment rate of $87.6 \%$, compared to an 
employment rate of barely $77 \%$ among the former grant holders who finished their master's in Mexico. The beneficiaries who obtained a doctorate abroad were $91.8 \%$ compared to $87.5 \%$ of those who graduated in Mexico. The main occupation of those graduates abroad was in the sector of superior education. The people who studied abroad worked mainly in higher education.

Similarly, Aggio et al (2017) carried out a study about the Argentinian program (BEC.AR), which was established in 2012 with the support of the Inter-American Development Bank. The program mainly promoted master's degrees in science and technology in institutions abroad. The paper analyzes the effect of 196 grants directed to postgraduate studies in Brazil and South Korea. They found that $60 \%$ of grant holders went straight back into work following their return, and a further $25 \%$ did so within six months. Concerning the level of income, they found that the proportion of former grant holders with above-average income increases was around 45\%, a much higher figure than that of the control group (approximately 28\%). These results could be biased because the control group was formed by applicants that did not get the program, i.e., selection bias.

The present study undertakes a causal analysis of the effect of the grants for master's studied abroad on labor income in a developing country using a rigorous combination of econometric techniques and following the incomes of the grant holders for three years after they returned to Ecuador. To correct any possible selection bias, which is very common in this type of program, the control group consisted of people who applied for a grant and were awarded one but did not use it and decided to get their master's degree in Ecuador. We found no impact during the first and second years after the holders returned to Ecuador. However, we see a positive and significant impact during the third year.

The following section provides a detailed description of the grant program to be evaluated. Then, we describe the database and the methodology used. After that, we show the results obtained. Finally, we discuss our results and introduce the conclusions in the final part.

\section{Description of the Grant Program and Country Background}

Ecuador is a lower-middle-income country (Note 1) characterized by high poverty levels (Note 2) as well as high inequality (Note 3). The gross enrollment rate of tertiary education is around $25 \%$, and postgraduate education is less than $1 \%$.

In 2010, a new Law of Higher Education (locally LOES) in Ecuador came into operation. This law created the National Secretariat for Higher Education, Science, Technology, and Innovation (SENESCYT). This institution is responsible for awarding grants at the undergraduate and postgraduate (master and $\mathrm{Ph} . \mathrm{D}$. programs) levels for studies in world-class universities.

The following table shows both the number of grants awarded and the budget allocated - which increased substantially from 2011 - in millions of dollars. The budget allocated to the whole grant project rose to US\$ 360 million in 2015.

Table 1. Number of grants and budget implemented

\begin{tabular}{ccc}
\hline Year & Grants & Amount (millions) \\
\hline $\mathbf{1 9 9 5 - 2 0 1 0}$ & 660 & 24 \\
$\mathbf{2 0 1 1}$ & 1754 & 37 \\
$\mathbf{2 0 1 2}$ & 3102 & 82 \\
$\mathbf{2 0 1 3}$ & 5392 & 168 \\
$\mathbf{2 0 1 4}$ & 5090 & 261 \\
$\mathbf{2 0 1 5}$ & 6063 & 360
\end{tabular}

Source: SENESCYT. Figures up to August 2015

This study focuses on evaluating the grant holders in two of the project's programs: Open Competition and Universities of Excellence. In both programs, the aim is to award full grants to applicants for their postgraduate studies in person in academic institutions located abroad. The Universities of Excellence (Note 4) program has a restricted list of study centres that make awards not only to postgraduate candidates but also to undergraduates. The values of the grants are higher than for the Open Competition program. Each year, the list of educational institutions changes the application requirements for both programs.

It is essential to mention that beneficiaries of the program had an obligation to return to the country once they have finalized their postgraduate studies. If they do not return to the country, they have to reimburse the total amount of 
the grant.

For this study, grant holders are defined as those who completed the process for the approval of the grant and took it up, in other words, traveled abroad to carry out their postgraduate studies. The awardees are those who were approved for the grant but did not sign the contract and travel. This is an important distinction because, as will be seen, it is part of the methodological strategy.

The following table shows the number of grant holders and awardees for each of the two programs being studied from 2011-2013.

Table 2. Grant holders and awardees per type of program and year

\begin{tabular}{ccccc}
\hline & \multicolumn{2}{c}{ Open competition } & \multicolumn{2}{c}{ Universities of Excellence } \\
\hline Year & Grant holders & Awardees & Grant holders & Awardees \\
& & & & \\
$\mathbf{2 0 1 1}$ & 759 & 312 & 0 & 0 \\
$\mathbf{2 0 1 2}$ & 1150 & 487 & 187 & 33 \\
$\mathbf{2 0 1 3}$ & 252 & 761 & 49 & 431 \\
\hline
\end{tabular}

\section{Source: SENESCYT}

The grants for the Open Competition program were worth from US\$ 65,437 to US\$108,332 for a master's program, depending on where the university was located, with Latin America qualifying for the lowest amount and Europe the highest. In the case of grants for a doctorate program, the amounts went from US\$16,588 to US\$217,649. There were 1,259 universities that qualified for Open Competition grants.

The grants for the Universities of Excellence program were worth up to US\$250,000, also depending on the location. For Latin America, the lowest amount was given, while the United States qualified for the highest amount. The grants were for master's anddoctoral degrees. There were 175 Universities of Excellence.

\section{Methodology}

\subsection{The Database}

As a starting point, we looked at a panel database from SENESCYT, with information about the awardees and holders of the grant programs and put it together with the database of the Tax Office of Ecuador (SRI), where data from the declaration of income is available. In refining these databases, we excluded those who had not registered any labor income during the period in question and those who had been awardees on several occasions. The total number of individuals was of 452 for the treatment group (holders), and 352 for the control group (awardees). The selected participants had complete information of incomes during 2009 and 2010, previous to the implementation of the program, as well as income information for 2014, 2015, and 2016, after the studies were completed and the beneficiaries returned to the country. From this total in the control group, the number of awardees that studied a master's program in Ecuador was 158. The control group was restricted to this group of individuals who studied a master's program in Ecuador.

\subsection{Identification Strategy}

When working with a panel database, if the same unit is observed on several occasions over time, there are many advantages regarding the possibility of finding causality. One of the main advantages when keeping the same unit across time is the possibility of correcting for unobservable effects that remain fixed in time.

Let us assume a linear model as follows:

$Y_{i t}=\beta_{0}+X_{i t} \beta+c_{i}+e_{i t}$

where the subscript $i$ refers to the unit (in this case, individuals), and the subscript $t$ refers to time. $Y_{i t}$ is the outcome variable (which may be the logarithm of income), $X_{i t}$ is a vector of control variables that change over time, $c_{i}$ is a component of unobservables at the level of individuals that does not change over time, and finally $e_{i t}$ is the idiosyncratic error term. The inclusion of the term $c_{i}$ makes it possible to correct for unobservable effects (provided that these are fixed in time). 
For our case, given that the objective is to evaluate the impact of a specific intervention, and following the methodology proposed by (Angrist \& Pischke, 2008), the following specification is appropriate:

$Y_{i t 1}=\beta_{0}+X_{i t 0} \beta+\alpha T_{i t}+Y_{i t o}+c_{i}+\tau_{t}+e_{i t}$

where $Y_{i t 1}, X_{i t}, c_{i}$ y $e_{i}$ are the same as in Equation (1), $\tau_{t}$ is the time effect for all individuals in the period $t$. In addition, the lagged dependent variable (2009 and 2010) is included as a control variable, and $T_{i t}$ is the variable that indicates whether the individual receives the treatment or not. The impact of the intervention would be given by the parameter $\alpha$.

In addition to the above, the probability of participation in the program can be used to match data based on observable characteristics since important information is available from the baseline (that is, for the years 2009 and 2010). There are many ways to carry out this matching: the nearest neighbor, the five nearest neighbors, using the whole distribution, etc. Recent developments in the matching literature indicate potential problems with the efficiency of the matching estimators when the bootstrap is used to calculate the standard errors (Abadie \& Imbens, 2011). Hirano et al., (2003)and Hirano \& Imbens (2001) proposed another matching method to obtain totally efficient estimators. It requires estimate Equation (2) using weighted least squares, where the weights used are 1 for the treated units and $\widehat{T}(X) /$ $(1-\widehat{T}(X))$ for the control units. (Note 5) In this case $\widehat{T}$ is the conditional probability of participation in the program (propensity score) estimated based on a probit model (selection equation) in the following format:

$T_{i}=X_{i t 0}^{\prime} \pi+\gamma Y_{i t 0}+v_{i t}$

where $T_{i}$ is a dummy that takes the value of 1 if the individual takes part in the program and zero if not; $X_{i t 0}^{\prime}$ is a vector of baseline variables that includes dummies: regional, program area, ethnic group, and sex; $Y_{i t 0}$ is the baseline result variable (log of income in 2009 and 2010) and $v_{i t}$ is an error term that follows a normal distribution.

This methodological strategy is based on a combination of fixed effects and lagged dependent variable model with a propensity score matching. In this way, the model is corrected by observable and unobservable variables, which do not change over time, to avoid possible bias in the estimation. In addition, the baseline matching enables that treatment and control groups are similar and comparable from the beginning.

Despite correcting for observables and non-observables, the combination of lagged dependent variable and fixed effect with matching does not allow to correct for possible selection bias, which is very common in programs of this kind. In other words, those who apply for the grants may have different non-observable characteristics from those who did not apply. For instance, they may be students with greater motivation and enthusiasm who take better advantage of the grant opportunities. Therefore, simply comparing beneficiaries with non-beneficiaries does not allow possible selection bias to be corrected. It was decided to choose as a control group those individuals - who we defined as awardees - who did apply for a grant and were even awarded one but did not manage to study abroad. The treated group, who applied for and received a grant but also used it, in other words, went to study overseas, were defined as grant holders.

This methodological strategy, known as "pipeline comparison", enables selection bias estimates to be corrected (Angrist, 1998). The main idea is that when using the pipeline comparison strategy, the effect of the non-observable variables in the selection process is corrected, whereas when using the fixed effects with lagged dependent variable model, non-observables fixed in time are corrected. Finally, the use of matching in the baseline allows to correct for observables at baseline.

As mentioned previously, to achieve robust results, we restricted the control group to those who carried out their postgraduate studies in Ecuador. The previous allows comparing people with similar levels of education (postgraduate level). We can compare the effect of getting the postgraduate degree by using the grant and studying at universities abroad versus getting the postgraduate degree in Ecuador and not using the grant.

\section{Results}

In this section, we present the results. The following table shows the means of some variables for treatment and control groups at baseline. The results indicate no significant differences in the variables of sex and ethnic group, but there are differences in pre-intervention incomes. 
Table 3. Means comparison of treatment and control groups before matching

\begin{tabular}{cccccc}
\hline Variable & Controls & sd & Treated & sd & p-value \\
\hline Sex & 0,316 & $-0,467$ & 0,358 & $-0,48$ & {$[0.334]$} \\
Afro-Ecuadorian & 0,006 & $-0,08$ & 0,004 & $-0,066$ & {$[0.787]$} \\
White & 0,025 & $-0,158$ & 0,042 & $-0,201$ & {$[0.287]$} \\
Indigenous & 0 & 0 & 0,004 & $-0,066$ & {$[0.158]$} \\
Mestizos & 0,937 & $-0,244$ & 0,927 & $-0,26$ & {$[0.672]$} \\
Montubio & 0,032 & $-0,176$ & 0,022 & $-0,147$ & {$[0.541]$} \\
Log of income 2009 & 9,719 & $-0,983$ & 9,373 & $-1,075$ & {$[0.000]$} \\
Log of income 2010 & 9,976 & $-0,834$ & 9,636 & $-0,968$ & {$[0.000]$} \\
$\mathbf{N}$ & $\mathbf{1 5 8}$ & & $\mathbf{4 5 2}$ & &
\end{tabular}

As indicated in the methodology, propensity score matching was used, as defined by (Hirano et al., 2003), to balance the baseline treatment and control groups. The selection model used for estimating the propensity score is presented in Annex 1 .

To confirm that the matching functions correctly, the regression results are presented in the following table. The independent variable is the treatment dummy and the regressors are the baseline incomes (in logs). There are no instances in which the coefficient is significant, which shows that matching succeeds in balancing baseline treatment and control groups in terms of incomes.

Table 4. Means comparison of treatment and control groups after matching

\begin{tabular}{llll}
\hline Variable & $\begin{array}{l}\text { Log of income } \\
\mathbf{2 0 0 9}\end{array}$ & $\begin{array}{l}\text { Log of income } \\
\mathbf{2 0 1 0}\end{array}$ & Sex \\
\hline & & & \\
T & -0.029 & -0.048 & -0.004 \\
Std. err & 0.084 & 0.065 & 0.034 \\
p-value & 0.728 & 0.457 & 0.904 \\
N & 610 & 610 & 610 \\
r2 & 0 & 0.001 & 0 \\
\hline
\end{tabular}

The dependent variable of the regression is the treatment variable. The first row reports the coefficient of the regression of T on each variable (log of income 2009, 2010 and sex). The second row reports the standard error, and the third row reports the p-value of the regression.

The results of the impact of the grant program are shown for the three years following the return of the grant holders: 2014, 2015, and 2016. As mentioned, Equation (2) is estimated using weighted OLS. To that effect, three specifications are used. Specification 1 includes just the treatment variable and the baseline log of income for 2009 and 2010. In addition to the variables in specification 1, specification 2 consists of the sex and ethnic group dummies. In addition to the variables in specification 2 , the third specification comprises the area of study and the country applied for.

The results are shown in the following table: 
Table 5. Impact of postgraduate studies abroad on employment income in 2014, 2015 and 2016

\begin{tabular}{llllllllll}
\hline \multirow{2}{*}{ Variable } & $\mathbf{2 0 1 4}$ & & \multicolumn{3}{c}{$\mathbf{2 0 1 5}$} & \multicolumn{5}{c}{ 2016 } \\
\hline T & Esp_1 & Esp_2 & Esp_3 & Esp_1 & Esp_2 & Esp_3 & Esp_1 & Esp_2 & Esp_3 \\
Std. Error & -0.378 & -0.378 & -0.54 & 0.165 & 0.165 & -0.029 & 0.253 & 0.253 & 0.087 \\
Inc_2009 & 0.034 & 0.034 & 0.034 & 0.033 & 0.033 & 0.032 & 0.034 & 0.034 & 0.033 \\
Std. Error & 0.339 & 0.339 & 0.323 & 0.339 & 0.339 & 0.32 & 0.387 & 0.387 & 0.366 \\
Inc_2010 & 0.021 & 0.021 & 0.02 & 0.021 & 0.021 & 0.019 & 0.021 & 0.021 & 0.02 \\
Std. Error & 0.724 & 0.724 & 0.648 & 0.716 & 0.716 & 0.621 & 0.662 & 0.662 & 0.58 \\
& 0.021 & 0.021 & 0.02 & 0.02 & 0.02 & 0.019 & 0.02 & 0.02 & 0.02 \\
Number of cases & 4880 & 4880 & 4880 & 4880 & 4880 & 4880 & 4880 & 4880 & 4880 \\
Number of groups & 610 & 610 & 610 & 610 & 610 & 610 & 610 & 610 & 610 \\
\hline
\end{tabular}

Specification 1 includes just the treatment dummy and the baseline log of income for 2009 and 2010. Specification 2 includes, in addition, the sex and ethnic group dummies. Specification three includes, in addition, the area of study and the country applied for. Legend: b/se.

There is a significant and negative effect for 2014 of about $5 \%$. No significant effect was found in 2015, and finally, there is a substantial and positive effect in 2016 of $8.7 \%$.

The results for 2014 and 2015, which are the initial years following the return of the grant holders, can be hypothetically explained in part by the initial difficulty of getting into the labor market in the country after being abroad for their studies.

\subsection{Heterogeneous Effects}

The data allows us to estimate heterogeneous effects by sex, income, and region of study.

Regarding sex, results are showed using the complete specification (3) in the following table.

Table 6. Impact of the program by sex on employment income in 2014, 2015 and 2016

\begin{tabular}{lllllll}
\hline Variable & $\begin{array}{l}\text { 2014 } \\
\text { Women }\end{array}$ & Men & $\begin{array}{l}\text { Women } \\
\text { Men }\end{array}$ & $\begin{array}{l}\text { Women } \\
\text { Men }\end{array}$ \\
\hline Std. Error & -0.44 & -0.66 & 0.094 & -0.17 & 0.464 & -0.12 \\
Inc_2009 & 0.048 & 0.042 & 0.048 & 0.036 & 0.056 & 0.037 \\
Std. Error & 0.193 & 0.294 & 0.345 & 0.206 & 0.49 & 0.242 \\
Inc_2010 & 0.034 & 0.024 & 0.034 & 0.02 & 0.04 & 0.021 \\
Std. Error & 0.257 & 0.487 & -0.072 & 0.509 & -0.075 & 0.518 \\
Number of cases & 0.04 & 0.025 & 0.04 & 0.021 & 0.047 & 0.022 \\
Number of groups & 1696 & 3184 & 1696 & 3184 & 1696 & 3184 \\
& 212 & 398 & 212 & 398 & 212 & 398 \\
\hline
\end{tabular}

Results for specification 3 are reported by sex. It includes as control variables the following: lagged log of incomes for 2009 and 2010, dummies for ethnic group, the area of study and the country applied for.

For women, results show a negative impact during the first year and then a positive and significant impact during the second and third year. During the second year and third year, the program's impact is around $9 \%$ and $46 \%$, respectively. In the case of men, results show a significant and negative impact of the program during the three years.

To analyze the impact by income, we defined two categories: low income, i.e., those below the average income in 2009, and high income, i.e., those above the average income in the year 2009. Results are shown in the following table. 
Table 7. Impact of the program by baseline income in 2014, 2015 and 2016

\begin{tabular}{lllllll}
\hline Variable & $\mathbf{2 0 1 4}$ & 2015 & & $\mathbf{2 0 1 6}$ & \\
\hline T & Low & High & Low & High & Low & High \\
Std. Error & -0.642 & -0.524 & -0.083 & -0.088 & 0.174 & -0.06 \\
Inc_2009 & 0.057 & 0.036 & 0.048 & 0.036 & 0.058 & 0.033 \\
Std. Error & 0.297 & 0.64 & 0.417 & 0.539 & 0.413 & 0.604 \\
Inc_2010 & 0.032 & 0.03 & 0.027 & 0.03 & 0.032 & 0.027 \\
Std. Error & 0.478 & 0.308 & 0.306 & 0.355 & 0.431 & 0.291 \\
& 0.034 & 0.027 & 0.028 & 0.027 & 0.034 & 0.025 \\
Number of cases & 2160 & 2720 & 2160 & 2720 & 2160 & 2720 \\
Number of groups & 270 & 340 & 270 & 340 & 270 & 340 \\
\hline
\end{tabular}

Results for specification 3 are reported by income. Low income is the group of those with incomes below the average in the year 2009. High income are those with incomes above the average in the year 2009. The regression includes as control variables the following: lagged log of incomes for 2009 and 2010, dummies for sex and ethnic group, the area of study and the country applied for.

The program's impact is significant and negative for the low-income group in 2014 and 2015 but becomes positive in 2016. The magnitude of the effect in 2016 is $17 \%$. In the case of those in the high-income group, on the other hand, the effect is always significant and negative, even in the year 2016.

The following table shows the results for the region of study applied for. We defined three groups: the United States of America, i.e., USA and Canada; Latin America; and other regions, i.e., Europe, Australia, and Asia.

Table 8. Impact of the program by region applied (in 2014, 2015 and 2016)

\begin{tabular}{lllllllllll}
\hline & $\mathbf{2 0 1 4}$ & & \multicolumn{3}{c}{$\mathbf{2 0 1 5}$} & & $\mathbf{2 0 1 6}$ & \\
Variable & USA & LAC & Other & USA & LAC & Other & USA & LAC & Other \\
\hline T & -0.641 & -0.437 & -0.58 & -0.245 & -0.146 & 0.038 & 0.632 & -0.068 & 0.086 \\
Std. Error & 0.104 & 0.061 & 0.042 & 0.094 & 0.057 & 0.039 & 0.088 & 0.06 & 0.042 \\
Inc_2009 & 0.122 & 0.414 & 0.244 & 0.067 & 0.283 & 0.269 & 0.258 & 0.337 & 0.341 \\
Std. Error & 0.084 & 0.037 & 0.024 & 0.076 & 0.035 & 0.023 & 0.071 & 0.037 & 0.024 \\
Inc_2010 & 0.626 & 0.415 & 0.53 & 0.68 & 0.431 & 0.445 & 0.387 & 0.452 & 0.414 \\
Std. Error & 0.09 & 0.037 & 0.027 & 0.081 & 0.035 & 0.025 & 0.076 & 0.037 & 0.026 \\
$\begin{array}{l}\text { Number of cases } \\
\text { Number }\end{array}$ & 512 & 1152 & 3216 & 512 & 1152 & 3216 & 512 & 1152 & 3216 \\
groups & & & & & & & & & \\
\hline
\end{tabular}

Results for specification 3 are reported by region applied. USA includes Unites States and Canada. LAC includes all Latin American countries. Other includes Europe, Australia and Asia. The regression includes as control variables the following: lagged log of incomes for 2009 and 2010, dummies for sex and ethnic group, and the area of study.

In the case of the USA, the results are significant and negative in the first and second year, and then become positive in the third year. The magnitude of the impact in the third year is 63\%. In Latin America, the results are significant and negative in the first and second years. In the third year, the results are not significant. Finally, in other regions, the results are significant and negative in the first and second year and become positive in the third year. The magnitude of the impact in the third year is $8 \%$.

In sum, the analysis of heterogeneous effects allows us to conclude that the program's impact concentrates on women, on the low-income group, and on those beneficiaries that studied in the USA and Europe.

\section{Discussion}

Ecuador initialized a grants program during 2011. The program's objective was to support graduate students to carry 
out postgraduate studies in high-level universities from all over the world. The budget dedicated to the program increased considerably. During the five years prior to the program, the total amount devoted to grants was 24 million dollars. Between 2011 and 2015, the total amount devoted to grants was 908 million dollars. Despite the significant amount dedicated to the program, no impact evaluation study was planned.

The literature available on the impact of this kind of program on beneficiaries' future income is limited. We did not find any study that evaluates the impact of grants programs on income using several years after the finalization of the postgraduate studies. In this regard, our paper allows us to analyze the evolution of the program's impact during three consecutive years after the grant holders returned to Ecuador. We found some evidence of improving the labor conditions of these programs in Latin America. Using several econometric techniques, we contribute to the literature evaluating the impact of an Ecuadorian program that consisted of delivering grants to study postgraduate program abroad. We found a significant and positive impact of the program on labor income. In addition, we found heterogeneous effects. The program's impact concentrates on women, on the low-income group, and on those beneficiaries that studied in the USA and Europe.

\section{Conclusions}

By combining administrative data, and econometric techniques, we evaluated the effect of the grants program on labor incomes during three years after the grant holders returned to Ecuador. The results show an initial negative effect during the first year, a non-significant effect during the second year, and a positive and significant effect during the third year. The initial results may be hypothetically explained by the difficulties experienced by the grant holders in incorporating into the labor market after studying abroad. Once in the labor market, the returned grant holders have incomes that increase over time more rapidly than those in the control group. Concerning this last result, it would be worth investigating the factors that cause this trend.

We found heterogeneous effects of the program. The effects are different by sex, income, and the country applied for. The analysis of heterogeneous effects allows us to conclude that the program's impact concentrates on women, on the low-income group, and on those beneficiaries that studied in the USA and Europe.

\section{Notes}

Note 1. In 2019, its per capita GDP was 4,138 in constant 2010 US dollars.

Note 2. Around 25\% using the poverty line of \$ 84 (per capita per month) in 2019.

Note 3. The Gini coefficient was 0,45 in 2019.

Note 4 . The total number of universities of excellence was 175 . The list was constructed using international rankings.

Note 5. When this weighting is used the average treatment in the treated units is obtained. In order to obtain the average treatment for the whole population, the weightings are $1 /(\widehat{T}(X))$ for the treated units and $1 /(1-\widehat{T}(X))$ for the control units. See (Hirano et al., 2003).

\section{References}

Abadie, A., \& Imbens, G. W. (2011). Bias-corrected matching estimators for average treatment effects. Journal of Business and Economic Statistics, 29(1), 1-11. https://doi.org/10.1198/jbes.2009.07333

Aggio, C. E., Milessi, D., \& Angelelli, P. (2017). El programa BEC.AR de Argentina: Impacto de sus becas para estudios de gestión de la innovación en el extranjero. Inter-American Development Bank. https://doi.org/10.18235/0000837

Angrist, J. (1998). Estimating the Labor Market Impact of Voluntary Military Service Using Social Security Data on Military Applicants. Econometrica, 66(2), 249-288. https://doi.org/10.2307/2998558

Angrist, J. D., \& Pischke, J. S. (2008). Mostly Harmless Econometrics: An empiricist's companion. Princeton University Press. https://doi.org/10.2307/j.ctvem4j72

Arora, A., \& Gambardella, A. (2005). The Impact of NSF Support for Basic Research in Economic. Annales d'Économie et de Statistique. https://doi.org/10.2307/20777571

Becker, G. S. (1962). Investment in Human Capital: A Theoretical Analysis. Journal of Political Economy, 70(5, Part 2), 9-49. https://doi.org/10.1086/258724

Becker, G. S. (1964). Human Capital. A theoretical and Empirical Analysis with Special Reference to Education (Third). University of Chicago Press.

Benavente, J. M., Crespi, G., Figal Garone, L., \& Maffioli, A. (2012). The impact of national research funds: A 
regression discontinuity approach to the Chilean FONDECYT. Research Policy, 41(8), 1461-1475. https://doi.org/10.1016/j.respol.2012.04.007

Benavente, J. M., Crespi, G., \& Maffioli, A. (2007). The Impact of National Research Fund: An Evaluation of the Chilean FONDECYT (Issue OVE/WP-03/07). Inter-American Development Bank.

Bonilla Landaverry, K., \& Kwak, J. S. (2015). Cooperación internacional y desarrollo de capacidad humana por programas becarios en Guatemala. Revista Naturaleza, Sociedad y Ambiente, 2(1), 83-109. https://doi.org/10.37533/cunsurori.v2i1.12

Chudnovsky, D., López, A., Rossi, M., \& Ubfal, D. (2006). Evaluating a Program of Public Funding of Scientific Activity. A Case Study of FONCYT in Argentina (Issue OVE/WP-12/06). Inter-American Development Bank.

Cubillos Calderón, C., Cáceres Mayorga, J., \& Erazo Caicedo, E. (2016). Impacto laboral de la Maestría en Educación de la Universidad del Tolima en sus graduados. Revista Latinoamericana En Ciencias Sociales, Niñez y Juventud, 14(1), 235-246. https://doi.org/10.11600/1692715x.14115200815

Fierro, I., \& Ponce, M. F. (2017). Movilidad internacional de estudiantes: tendencias entre mercados emergentes como herramienta estratégica para las oficinas de reclutamiento de estudiantes internacionales. INNOVA Research Journal, 2(8), 117-138. https://doi.org/10.33890/innova.v2.n8.1.2017.353

Hirano, K., \& Imbens, G. W. (2001). Estimation of causal effects using propensity score weighting: An application to data on right heart catheterization. Health Services and Outcomes Research Methodology, 2, 259-278. https://doi.org/10.1023/A:1020371312283

Hirano, K., Imbens, G. W., \& Ridder, G. (2003). Efficient estimation of average treatment effects using the estimated propensity score. Econometrica, 7l(4), 1161-1189. https://doi.org/10.1111/1468-0262.00442

Luchilo, L. (2009). Los impactos del programa de becas del CONACYT mexicano: un análisis sobre la trayectoria ocupacional de los ex becarios (1997-2006). CTS: Revista Iberoamericana de Ciencia, Tecnología y Sociedad, 5(13), 175-205. https://www.redalyc.org/articulo.oa?id=92415269010

Mendoza, M. (2014). Racionalidades e intereses de cientistas sociales para realizar un magíster en el extranjero: implicancias para el programa Becas Chile. Calidad En La Educación, 40, 269-294. https://doi.org/10.4067/s0718-45652014000100009

Mincer, J. (1970). The distribution of labor incomes: A survey. With special reference to the human capital approach. Journal of Economic Literature, 8(1), 1-26. http://www.jstor.org/stable/2720384

Psacharopoulos, G., \& Patrinos, H. A. (2004). Human capital and rates of return. International Handbook on the Economics of Education, 1-57. https://doi.org/10.4337/9781845421694.00006

Schultz, T. (1975). The Value of the Ability to Deal with Disequilibria. Journal of Economic Literature, 13(3), 827-846. https://www.jstor.org/stable/2722032

Ubfal, D., \& Maffioli, A. (2011). The Impact of Funding on Research Collaboration: Evidence from a Developing Country. Research Policy, 40(9), 1269-1279. https://doi.org/10.1016/j.respol.2011.05.023

Vincent-Lancrin, S. (2011). La educación superior transfronteriza: tendencias y perpectivas. Innovación Educativa, 11(56), 21-36. https://www.redalyc.org/articulo.oa?id=179421438003 


\section{Annex 1}

Probit model of program participation

\begin{tabular}{lllllllll}
\hline T & dF/dx & Std.Err. & $\mathbf{z}$ & $\mathbf{P}>\mathbf{z}$ & x-bar & 95\% & C.I. & ] \\
\hline Sex & 0,014 & 0,027 & 0,540 & 0,591 & 0,349 & $-0,038$ & 0,067 \\
White & 0,134 & 0,125 & 0,850 & 0,396 & 0,038 & $-0,111$ & 0,380 \\
Mestizo & 0,047 & 0,191 & 0,250 & 0,800 & 0,933 & $-0,327$ & 0,420 \\
Montubio & $-0,049$ & 0,209 & $-0,240$ & 0,807 & 0,025 & $-0,459$ & 0,361 \\
Log of income 2009 & $-0,027$ & 0,018 & $-1,510$ & 0,130 & 9,463 & $-0,062$ & 0,008 \\
Log of income 2010 & $-0,055$ & 0,021 & $-2,660$ & 0,008 & 9,738 & $-0,096$ & $-0,015$ \\
\hline
\end{tabular}

Obs. P $0.7401316 \quad$ Pred. P 0.7465435

Results of the program participation model used to estimate the propensity score in order to compute the weights used to estimate equation (2). Based on Hirano, Imbens and Ridder (2003).

\section{Copyrights}

Copyright for this article is retained by the author(s), with first publication rights granted to the journal.

This is an open-access article distributed under the terms and conditions of the Creative Commons Attribution license (http://creativecommons.org/licenses/by/4.0/). 